\title{
Elisabeth Arnould-Bloomfield, Georges Bataille, la terreur et les lettres
}

\section{Michela Gardini}

\section{(2) OpenEdition}

1 Journals

\section{Edizione digitale}

URL: http://journals.openedition.org/studifrancesi/5756

DOI: $10.4000 /$ studifrancesi.5756

ISSN: 2421-5856

\section{Editore}

Rosenberg \& Sellier

\section{Edizione cartacea}

Data di pubblicazione: 1 septembre 2011

Paginazione: 453

ISSN: 0039-2944

\section{Notizia bibliografica digitale}

Michela Gardini, «Elisabeth Arnould-Bloomfield, Georges Bataille, la terreur et les lettres», Studi Francesi [Online], 164 (LV | II) | 2011, online dal 30 novembre 2015, consultato il 13 janvier 2021. URL: http:// journals.openedition.org/studifrancesi/5756 ; DOI: https://doi.org/10.4000/studifrancesi.5756

Questo documento è stato generato automaticamente il 13 janvier 2021.

\section{(c) $(1) \&$}

Studi Francesi è distribuita con Licenza Creative Commons Attribuzione - Non commerciale - Non opere derivate 4.0 Internazionale. 


\title{
Elisabeth Arnould-Bloomfield, Georges Bataille, la terreur et les lettres
}

\author{
Michela Gardini
}

\section{NOTIZIA}

ELISABETH ARNOULD-BLOOMFIELD, Georges Bataille, la terreur et les lettres, Villeneuve d'Ascq, Presses Universitaires du Septentrion, 2009, 226 pp.

1 L'intento dichiarato dall'A. è quello di rinnovare lo sguardo critico su Georges Bataille, partendo dalla considerazione secondo cui ancora attualmente la critica è ipotecata all'analisi proposta dagli autori di «Tel Quel» che, per quanto ricca e illuminante, si rivela tuttavia parziale, non avendo essa sufficientemente esplorato il profondo cambiamento che il pensiero e l'opera di Bataille conobbero a partire dal 1939. È questo un anno di svolta, nel quale Bataille registra sia il fallimento dell'esperienza di «Acéphale» che la morte dell'amata Laure, quest'ultimo «l'événement qui, plus qu'un autre, sert de catalyseur à une réorientation de la pensée bataillienne» (p. 20). A partire da questo momento Bataille, sostiene l'A., dopo aver abbandonato una prima fase violentemente trasgressiva, tanto "terroristica" quanto antiretorica, si avvicina con rinnovato interesse alla letteratura, anche nella direzione di un ritorno alla retorica, sia accostandosi alle opere di altri scrittori, quali Paulhan e Proust, sia redigendo egli stesso opere letterarie, come per esempio Madame Edwarda e L'Alleluiah. E. ArnouldBloomfield propone dunque piuttosto un ritorno alla lettera dell'opera batailliana, depurata il più possibile delle sovrastrutture critiche maggiormente interessate alla sua apoeticità. In questa prospettiva, rintraccia nell'immaginario dei fiori il filo rosso che, tra terrore e poesia, sacrificio e retorica, contiene il senso più profondo del suo pensiero, dai girasoli di Van Gogh alla rosa di Laura ai gigli di virgiliana memoria (Manibus date lilia plenis) che chiudono L'Expérience intérieure. Pur senza disconoscere l'originalità di tale percorso, ci sembra tuttavia una mancanza il fatto che l'A. non menzioni l'edizione nella Bibliothèque della Pléiade delle opere narrative di Bataille (Georges Bataille, Romans et récits, Gallimard, 2004), un testo imprescindibile per quanti 
si accostino all'opera di Bataille, tenuto conto anche della prefazione di Denis Hollier, del lavoro del curatore Jean-François Louette e dei suoi collaboratori. Riteniamo infatti che l'importanza della letteratura per Bataille, opportunamente sottolineata, non vada tuttavia necessariamente letta in opposizione rispetto a qualcosa d'altro, ricordando piuttosto come essa attraversi interamente l'opera di Bataille, sin dall'inizio, intrecciandosi altresì, in un dialogo proficuo e costante, con altri campi della cultura, dall'antropologia all'arte, dal collezionismo alla religione. 